sponses to a request for proposals and choose those most worthy of support.

Last year, for example, the MonsantoWashington University committee funded about a third of the proposals it received; at any given time, the $\$ 9$ million a year from Monsanto is supporting about 50 projects. Those rejected are free to find other support, typically from NIH; the same would be true at Scripps. The concurrence rate between university and company scientists "is very high", says David Kipnis, who helped to negotiate the agreement and who was until recently chairman of the department of medicine at the medical school.

No such council exists in the current agreement between Scripps and Johnson \& Johnson (J\&J) of New Jersey, on which the company spent $\$ 10.5$ million last year. (As in the Sandoz agreement, J\&J spends some of its money on specific projects with the rest going into a general pot for use as Scripps sees fit.) Instead, there is a medical utility evaluation committee that discusses the results of work by Scripps scientists; anyone doing work deemed of interest to the company is asked to submit a proposal, which is reviewed by several J\&J officials. "We think that the council is a much better way of doing things", says William Beers, a senior vice president at Scripps. "It's something that scientists are already used to."

Healy last week testified that the agreement "forbids too many things and runs counter to the spirit of science". In particular, she is concerned about the authority of Sandoz officials to terminate research projects that they feel are ripe for development and to review existing agreements between Scripps researchers and other companies as they expire.

Beers admits that at present J\&J "does not have the right to intercede" on the fate of existing agreements with other companies but that under the Sandoz contract "we will have to go to them [Scripps] first". However, he says that Sandoz would not assume control of a project until it is ready for commercialization and that Scripps "is not in the business of developing drugs". Speaking only about his university's collaboration with Monsanto, Kipnis says that "most of the time it's the other way around: a scientist thinks that he has a cure for something and wants it to be developed right away and the company says it's not interested."

Lawyers for Scripps believe that Healy has spent insufficient time reading a lengthy technical document and that her comments misinterpret the spirit of the contract. Healy acknowledges that NIH lawyers had barely a day to review the agreement, which may also explain why her sharpest criticism did not appear in the advance version of her testimony that is routinely reviewed by White House officials. The Clinton administration has no official position on the controversy, which arose shortly after the agreement was announced in early December.

Jeffrey Mervis

\title{
British JET workers protest against hiring discrimination
}

Oxford. Fusion research at the Joint European Torus (JET) laboratory at Culham in Oxfordshire continues to be disrupted by British scientists striking in protest against future employment barriers based on age and citizenship.

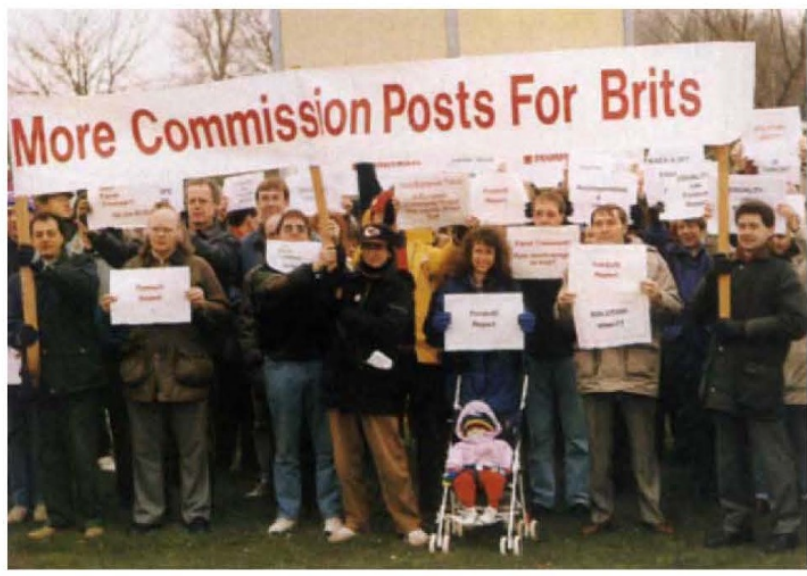

Striking JET workers and their families offer their views.

JET is due to close at the end of 1996, and many of its 420 employees hope to be employed by other research projects supported by the European Commission (EC). That has already happened to 13 of the 20 staff made redundant last year. But the remaining seven - all Britons - have failed to find work partly because of an EC policy that new employees must be under 35 years old for junior posts and under 50 for senior posts.

British workers at JET are employed by the UK Atomic Energy Authority, while

\section{NASA shrinks station, elevates life sciences}

Washington. Facing a mismatch between money and ambition, US President Bill Clinton has told the National Aeronautics and Space Administration (NASA) to design a smaller space station with fewer functions than the one now being built. The new station will orbit for half the scheduled 30 years, will be easier to maintain and may not be permanently inhabited. Some $40-50$ engineers and scientists from NASA, industry, universities and the project's partners in Europe, Japan and Canada have been given until 1 June to propose options.

The overall cost to build the new station will be "significantly less" than the former estimate of \$31 billion, according to NASA Administrator Daniel Goldin. Lifetime operational costs for the facility — which have been estimated to be as high as $\$ 100$ billion - will be reduced by half. NASA has al- their colleagues are employed by EC's nuclear agency, Euratom. As a result, British researchers are treated as external applicants when applying for positions at other EC projects.

Some 150 workers participated in the most recent strike, held on 5 March. It was a response to the rejection on 26 February by the JET Council of their request to be made temporary EC employees. Last September, an independent panel appointed by Filippo Pandolfi, then EC research commissioner, recommended that the AEA staff at JET should be given temporary EC contracts or at the least that they should in future receive preferential treatment over outside applicants. The JET Council rejected the first suggestion and endorsed the second, which it has no power to implement.

The only concession so far to British workers has been to raise the age limit to 50 for all vacancies at the forthcoming International Thermonuclear Experimental Reactor (ITER) project. But representatives of the striking workers say that the change is too little, too late: ITER is only one of many EC projects, and it will employ only a hundred people in its initial stage.

Oliver Tickel

ready spent $\$ 8.5$ billion on the project, and the redesign team, will try to retain as much of that work as possible. Clinton wants the station to be completed within five years and he wants NASA to begin conducting research - whether on the space station, on a space shuttle modified for long stays in orbit or on a Russian orbiting station — by 1997.

Last week, on the same day as Goldin announced the station redesign, NASA also announced changes in the organization of its research programme. New offices within the agency will be responsible for life and microgravity sciences; advanced concepts and technology; planetary science and astrophysics; and Earth science. The reorganization is consistent with NASA's emphasis on biological research as an essential activity for the station.

Tony Reichhardt 